\title{
Multi-step process of human breast carcinogenesis: A role for BRCA1, BECN1, CCND1, PTEN and UVRAG
}

\author{
TAO WU $^{1 *}$, YI LI $^{2 *}$, LI GONG $^{3 *}$, JIAN-GUO LU ${ }^{1}$, XI-LIN DU ${ }^{1}$, \\ WEN-DONG ZHANG ${ }^{3}$, XIAN-LI HE ${ }^{1}$ and JUN-QING WANG ${ }^{4}$
}

Departments of ${ }^{1}$ General Surgery, ${ }^{2}$ Obstetrics and Gynecology, ${ }^{3}$ Pathology, and ${ }^{4}$ Rehabilitation, Tangdu Hospital, The Fourth Military Medical University, Xi'an 710038, P.R. China

Received July 8, 2011; Accepted October 7, 2011

DOI: $10.3892 / \mathrm{mmr} .2011 .634$

\begin{abstract}
In the female population in Asia, systematic investigation concerning alterations in cancer-related genes in breast carcinoma is rare, and the correlation among oncogene or suppressor gene expression with tumor cell apoptosis, cell cycle regulation and tumor cell autophagy remains to be clarified. In this study, a tissue microarray consisting of 360 individual samples from three different breast tissues was generated. By comparing the expression of the tumor-suppressor genes (BRCA1, BECN1, CCND1, PTEN and UVRAG) in ductal breast cancer and normal breast tissues, respectively, we were able to assign changes in the expression of these mRNAs to specific stages and allocate them to define the roles in the multi-step process of breast carcinogenesis. Tumor-suppressor genes, such as BRCA1 and BECN1, usually had lower signals in the carcinomatous tissues (10.2 and 6.6\%) compared to the normal tissues (31 and 32.6\%), while stronger positive dots (positive cells $>30 \%$ ) usually existed in the normal tissues. The patients in the oldest age group had the lowest expression rate. Only BECN1 and CCND1 expression showed a significant association with patient age $(\mathrm{p}=0.030$ and $\mathrm{p}=0.003)$. A significant association was observed between $B R C A 1$ and $B E C N 1$ expression and tumor size $(\mathrm{p}=0.028$ and $\mathrm{p}=0.021)$. $B E C N 1$ gene expression was positively correlated with $U V R A G$ and PTEN expression $(\mathrm{p}=0.006$ and $\mathrm{p}=0.000)$. $C C N D 1$ was negatively correlated with PTEN, BECN1 and BRCAl expression $(\mathrm{p}=0.011, \mathrm{p}=0.000$ and $\mathrm{p}=0.000)$. Abnormal expression of
\end{abstract}

Correspondence to: Professor Xian-Li He, Department of General Surgery, Tangdu Hospital, The Fourth Military Medical University, Xi'an 710038, P.R. China

E-mail: xianlhe@gmail.com

Professor Jun-Qing Wang, Department of Rehabilitation, Tangdu Hospital, The Fourth Military Medical University, Xi'an 710038, P.R. China

E-mail:tdkfk1@fmmu.edu.cn

*Contributed equally

Key words: ductal breast cancer, apoptosis, cell cycle, autophagy, mRNA in situ hybridization
BRCA1, BECN1, CCND1, PTEN and $U V R A G$ may play a role in human breast carcinogenesis through dysregulated mRNA expression. Overexpressed CCND1 may shorten the G1 phase of the cell cycle, suppress cell apoptosis and contribute to the formation of invasive ductal carcinoma (IDC).

\section{Introduction}

Breast cancer is the second most common type of cancer after lung cancer (10.4\% of all cancer incidence, both genders counted) and the fifth most common cause of cancer-related mortality (1). In 2005, breast cancer caused 502,000 deaths worldwide ( $7 \%$ of cancer mortality; almost $1 \%$ of all mortality) (2). During recent years, the incidence rate of breast carcinoma has gradually increased in Asia and has become the second most common malignant tumor of Chinese women, with the number of new cases currently at approximately 60,000 in China annually (3). Ductal breast cancer is the most common type of breast cancer. Worldwide, 70-80 out of every 100 breast cancers diagnosed are of this type.

Breast cancer is considered to be the final outcome of multiple environmental and hereditary factors. Some of these factors include: i) lesions to DNA, such as genetic mutations (4); ii) failure of immune surveillance (5); iii) abnormal growth factor signaling in the interaction between stromal and epithelial cells facilitating malignant cell growth; iv) inherited defects in DNA repair genes, such as BRCA1, BRCA2 and p53. Although numerous epidemiological risk factors have been identified, the cause of any individual's breast cancer is often unknown. In other words, epidemiological research provides information on the patterns of breast cancer incidence across certain populations, but not in a given individual (6).

Oncogenes act cooperatively with other genetic or epigenetic changes. In breast cancer, there has been much attention focused on oncogenic components of the cell signaling system, an example of which is CCND1. These are involved in transducing and modulating this signal, which results in a number of end events, including cell proliferation, alterations in drug sensitivity and DNA repair, angiogenesis, apoptosis and protease activity. The gene encoding CCNDI is located on chromosome 11q13 and has been found to be overexpressed in $40-50 \%$ of invasive breast cancers and amplified in $10-20 \%$ of cases (7). When CCND1 is complexed with its CDK partner, 
the $\mathrm{pRb}$ tumor-suppressor protein is phosphorylated, releasing the transcriptional factor E2F and inducing proteins required for DNA synthesis. For example, breast cancer patients who have high levels of CCND1 following mastectomy are at a higher risk for cancer recurrence than women with low levels of CCNDI (8).

$B R C A-1$ codes for a protein of 1,863 amino acids, with a number of structural domains that hint at its function (9). A RING finger domain encodes a protein-binding domain at the amino terminus (10). BRCA-associated ring domain (BARD1) is a protein found to interact with BRCA-1 in the RING domain, and it may prove to have a tumor-suppressor function of its own. Two repeats in the carboxy terminus are similar to those observed in numerous DNA repair enzymes, including Rad9. Following genotoxic insult, BRCA-1 protein, along with BARD1 and Rad51, has been shown to localize to areas of damaged DNA, supporting a role in the regulation of transcription as well as in the repair of double-stranded DNA (11). BRCA-1 protein with cyclin-dependent kinase and cyclin-A, D may also regulate the cell cycle.

The PTEN protein is a lipid phosphatase with putative tumor-suppressing abilities, including inhibition of the PI3K/ Akt signaling pathway. Inactivating mutations or deletions of the PTEN gene, which result in hyper-activation of the PI3K/ Akt signaling pathway, are increasingly being reported in human malignancies, including breast cancer, and have been related to features of poor prognosis and resistance to chemotherapy and hormone therapy (12). Inherited PTEN mutations, observed in Cowden syndrome, have been shown to increase the risk of breast and ovarian cancers (among others), although mutation of this gene in sporadic cases is uncommon $(13,14)$.

The BECN1 gene is localized to chromosome 17q21, a locus that is deleted in $50 \%$ of breast cancers (15). Recent studies have demonstrated that autophagy is related closely to the occurrence and development of tumors. Autophagic activity was found to be significantly reduced in beclin 1-deficient cells as assessed in vivo in mutant mice or in vitro in BECN1/ embryonic stem (ES) cells. UV-irradiation resistance-associated gene $(U V R A G)$, as a BECN1-interacting protein, associates with BECN1, enhances phosphatidylinositol-3-OH kinase class III [PI(3)KC3] activity and induces autophagosome formation. Expression of UVRAG may suppress the tumorigenicity and proliferation of human colon cancer cells, and it promotes autophagy in a manner that is interdependent of BECN1 (16). A number of studies have suggested that Bif-1 joins the UVRAG-BECN1 complex as a potential activator of autophagy and tumor suppressor $(17,18)$.

Currently, all breast cancer cases should be tested for the expression, or a detectable effect, of the estrogen receptor (ER), progesterone receptor (PR) and HER2/neuproteins. These tests are usually carried out by immunohistochemistry, and a few involve in situ hybridization to test for oncogenes (CCND1) and tumor-suppressor genes (BRCA1, BECN1, PTEN and $U V R A G)$. It is crucial to know whether the oncogene and suppressor gene RNA expression is different, comparing different steps in onset and progression of the disease. In addition, most studies of breast cancer-related genes have focused on gene expression and have reported less on the correlation between gene expression and cancer. In addition, studies on cancer-related genes have focused on Caucasian female patients. There are few reports associated with Asian females. Since the carcinogenesis of breast carcinoma may show discrepancies among various ethnicities (Caucasian female and Asian female), detailed information on gene amplification and abnormal expression of cancer-related genes in Chinese patients with breast carcinoma and its correlation with pathological parameters needs to be investigated.

\section{Materials and methods}

Tissue sample. The tissue samples used in this study were from patients who underwent surgery at the Department of General Surgery, Tangdu Hospital,The Fourth Military Medical University, Xi'an, China, from 2006 to 2009. All of the patients were Chinese and their mean age was 41.6 years.

Tissue microarray (TMA) construction. Tissue blocks of grossly apparent carcinoma and non-pathologic organs were trimmed to approximately $1.5 \times 1.5 \times 0.3 \mathrm{~cm}$ and were fixed immediately in $4 \%$ paraformaldehyde in phosphate-buffered saline (1\% DEPC-PBS), pH 7.4, for 24 h. They were then dehydrated through an ethanol gradient and embedded in paraffin. Representative areas of the various lesions were carefully selected on H\&E-stained sections and marked on individual paraffin blocks. The tissue cores were precisely arrayed into a new paraffin block using a TMA workstation (Beecher Instruments, Silver Spring, MD, USA). The final TMA consisted of 360 1-mm diameter TMA cores, each spaced at $0.8 \mathrm{~mm}$ from between core centers. An H\&E-stained section was reviewed to confirm the presence of morphologically representative areas of the original lesions.

Preparation of digoxigenin-labelled probes for RNA in situ hybridization (IHS). cDNAs from 5 different human genes were cloned in order to synthesize ISH riboprobes. The cDNA was obtained from the total RNA of normal breast and breast cancer tissues by reverse transcription coupled with PCR by the use of primers (Table I). The cDNA was cloned into the pGEM-T (cat. \#TM042) vector to obtain the pGEM-T/BECN1 (333-992), pGEM-T/BRCA1 (5046-5728), pGEM-T/CCND1 (396-895), pGEM-T/PTEN (1414-1956) and pGEM-T/UVRAG (1323-2149) plasmids, which were used to synthesize riboprobes for RNA in situ hybridization assay.

The cDNA-containing plasmids were linearized, gel-isolated and used as templates for antisense and sense digoxigenin (DIG)-labeled riboprobe synthesis (Boehringer Mannheim, Mannheim, Germany). The transcription mixture (50 $\mu \mathrm{l}$ ) included $1 \mu \mathrm{g}$ of linearized template cDNA, ATP, GTP and CTP at $1 \mathrm{mM}$ each, UTP $0.7 \mathrm{mM}$, DIG-UTP $0.3 \mathrm{mM}$, DTT $10 \mathrm{mM}$, RNase inhibitor (1 U/ $\mu$ l of transcription mix) and $\mathrm{T} 3$ or T7 RNA polymerase $(1 \mathrm{U} / \mu 1$ of transcription mix). Transcription was performed for at least $2 \mathrm{~h}$ at $37^{\circ} \mathrm{C}$. The template cDNAs were then digested using RNase-free DNase $\left(2 \mu \mathrm{l}\right.$ at $1 \mathrm{U} / \mu 1,30 \mathrm{~min}$ at $\left.37^{\circ} \mathrm{C}\right)$, and all reactions were terminated by adjusting the reaction volume to $100 \mu \mathrm{l}$ with Tris/EDTA (10/1 mM, pH 8.0). The riboprobes were then purified through two precipitation steps by addition of

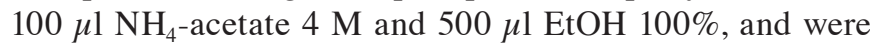
centrifuged for $30 \mathrm{~min}$ at $4^{\circ} \mathrm{C}$ in a microfuge. The pellet was resuspended in $200 \mu \mathrm{l}$ DEPC-treated water. The synthesized 
Table I. Primer sequences used for amplifying the studied genes.

\begin{tabular}{lll}
\hline Primer & & \multicolumn{1}{c}{ Sequence 5'-3' } \\
\hline BECN1 & Sense & AGCCATTTATTGAAACTCCTCG \\
& Antisense & TATTGATTGTGCCAAACTGTCC \\
BRCA1 & Aense & GCTGCTCATACTACTGATACTGC \\
& Antisense & GCTACACTGTCCAACACCCACT \\
CCND1 & Sense & TGGATGCTGGAGGTCTGCGAGGAA \\
& Antisense & AGGCGGTAGTAGGACAGGAAGTTGTT \\
PTEN & Sense & AGGGACGAACTGGTGTAATGAT \\
& Antisense & CACGCTCTATACTGCAAATGCT \\
SVRAG & Sense & CTGTTGCCCTTGGTTATACTGC \\
& Antisense & GATGATTTCTTCTGCTTGCTCC
\end{tabular}

riboprobe (5-10 $\mu \mathrm{g})$ was obtained from $1 \mu \mathrm{g}$ of cDNA matrix. The DIG-incorporation into the probes was controlled by dot spots. DIG was visualized with an anti-DIG antibody coupled to alkaline phosphatase.

RNA in situ hybridization. Deparaffinized sections mounted on Denhardt-coated glass slides were treated with pepsin $\left(0.25 \mathrm{mg} / \mathrm{ml}\right.$ in DEPC $\left.\mathrm{H}_{2} \mathrm{O}-\mathrm{HCl}\right)$ for $25-30 \mathrm{~min}$ at $37^{\circ} \mathrm{C}$ in a water bath. The treated sections were then processed for in situ hybridization at $41-48^{\circ} \mathrm{C}$ for $16-24 \mathrm{~h}$. The hybridization mixture contained the labeled oligonucleotide probe, $50 \%$ formamide, $10 \mathrm{mmol} / 1$ Tris-HCl, $1 \mathrm{mmol} / \mathrm{l}$ vanadyl-ribonucleoside complex (Sigma 94740, St. Louis, MO, USA), 1 mmol/1 CTAB (Sigma 855820), pH 7.0, 0.15 mol/1 NaCl, 1 mmol/1 EDTA, pH 7.0, $1 \mathrm{X}$ Denhardt's mixture and $10 \%$ dextran sulfate. Hybridization was performed in a box saturated with a $5 \mathrm{X}$ SSC-50\% formamide solution to avoid evaporation. Due to the different probes, a different pilot-experiment was applied to produce optimum results. Post-hybridization, slides were washed three times for $30 \mathrm{~min}$ in $0.1 \mathrm{~mol} / 1 \mathrm{TBS}$ at room temperature, then treated with $1 \%$ blocking reagent (Boehringer Mannheim) in TBS (100 mmol/1 Tris, pH 7.5, $150 \mathrm{mmol} / \mathrm{l} \mathrm{NaCl})$ with $0.03 \%$ Triton X-100 for $30 \mathrm{~min}$ at room temperature and incubated for $30 \mathrm{~min}$ with an anti-DIG alkaline phosphatase-conjugated antibody (Boehringer Mannheim; 11093274910) diluted 1:500 in TBS, $0.03 \%$ Triton X-100 and $1 \%$ blocking reagent. After washing three times for $15 \mathrm{~min}$ in TBS, $0.05 \%$ Tween, slides were rinsed in DAP-buffer $(100 \mathrm{mmol} / \mathrm{l}$ Tris, $100 \mathrm{mmol} / \mathrm{l} \mathrm{NaCl}$ and $50 \mathrm{mmol} / 1 \mathrm{MgCl}_{2}, \mathrm{pH} 9.5$ ) and, subsequently, hybridization signals were visualized using nitroblue tetrazolium and 5-brom-4-chlor-3-indolyl phosphate as substrates.

Statistical analysis. All cases were first grouped as positive or negative to calculate the percentages of positive and negative cases, as described. The $\chi^{2}$ contingency test was used to evaluate the differences among groups. Analyses were performed using the statistical package SPSS 10.0 (SPSS, Chicago, IL, USA). $\mathrm{P}<0.05$ was considered to denote statistical significance.

\section{Results}

Clinicopathological data. The clinical characteristics of the primary tumors are shown in Table II. A total of 105 patients
Table II. Histopathological characteristics of 250 cases of breast cancer.

\begin{tabular}{lr}
\hline Tumor type & $\mathrm{n}(\%)$ \\
\hline Invasive ductal carcinoma & $250(98.8)$ \\
Invasive lobular carcinoma & $2(0.8)$ \\
Mucinous carcinoma & $1(0.4)$ \\
Histological grading & \\
G1 & $44(17.6)$ \\
G2 & $161(64.4)$ \\
G3 & $45(18.0)$ \\
Tumor extent & \\
pT1 (pT1a, pT1b, pT1c) & $23(9.20)$ \\
pT2 & $168(67.2)$ \\
pT3 & $26(10.4)$ \\
pT4 (pT4a, pT4b, pT4c, pT4d) & $33(13.2)$ \\
Lymph node status & \\
pN0 & $89(35.6)$ \\
pN1 & $127(50.8)$ \\
pN2 & $30(12.0)$ \\
pNX & $4(1.6)$ \\
Metastases & \\
pM0 & \\
pM1 & \\
pMX & $4(37.6)$ \\
\hline
\end{tabular}

were initially treated with breast conserving surgery, 125 by mastectomy and 11 by subcutaneous mastectomy. Information on adjuvant treatment was available for 97 cases. There were 250 invasive ductal carcinomas (IDCs), 2 lobular carcinomas and 1 mucinous carcinoma. In all breast carcinomas, tumors were moderately and poorly differentiated in 161 cases $(64.4 \%)$ and 45 cases $(18.0 \%)$. A total of 44 out of 250 cases $(17.6 \%)$ were well-differentiated (Table II).

RNA in situ hybridization study. RNA in situ hybridization differences for BRCA1, BECN1, CCND1, PTEN and UVRAG were found following categorization of the variables according 


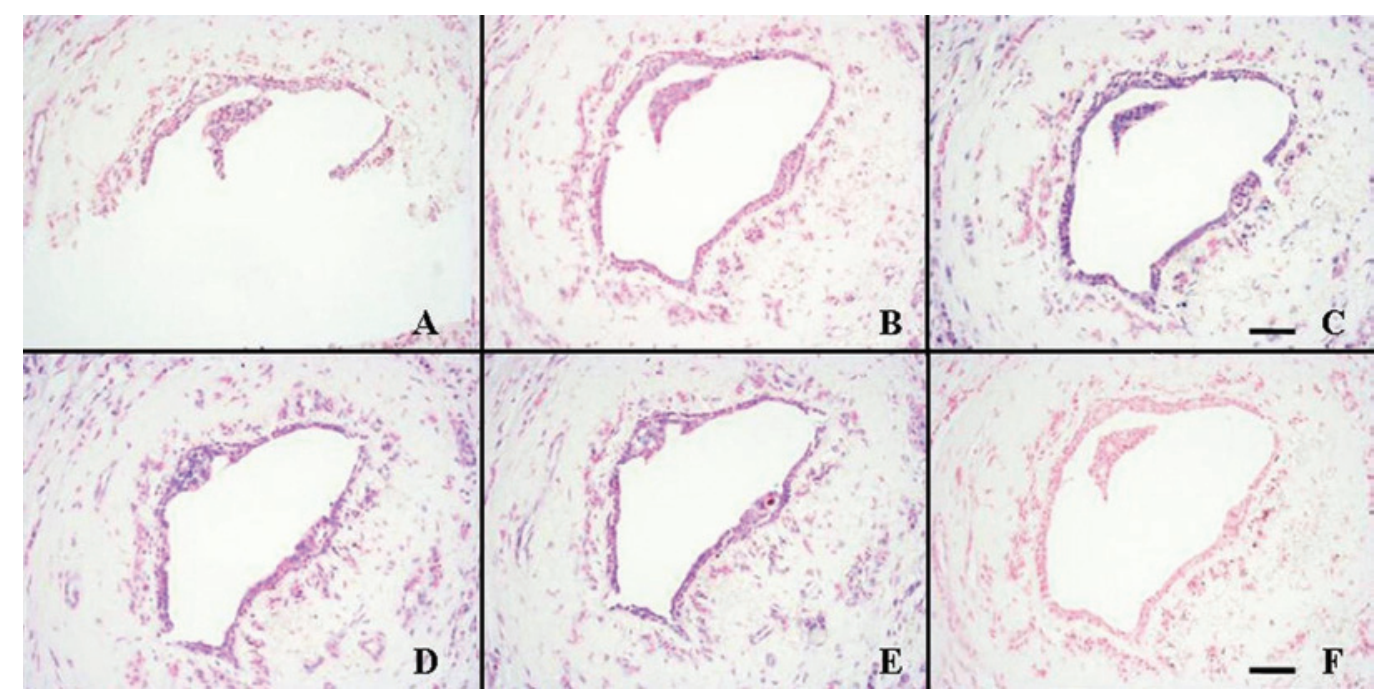

Figure 1. RNA in situ hybridization study in invasive ductal carcinoma and a negative control. RNA expression of (A) BRCA1, (B) BECN1, (C) CCND1, (D) PTEN and (E) UVRAG. (F) Negative control. Scale bars, $50 \mu \mathrm{m}$.

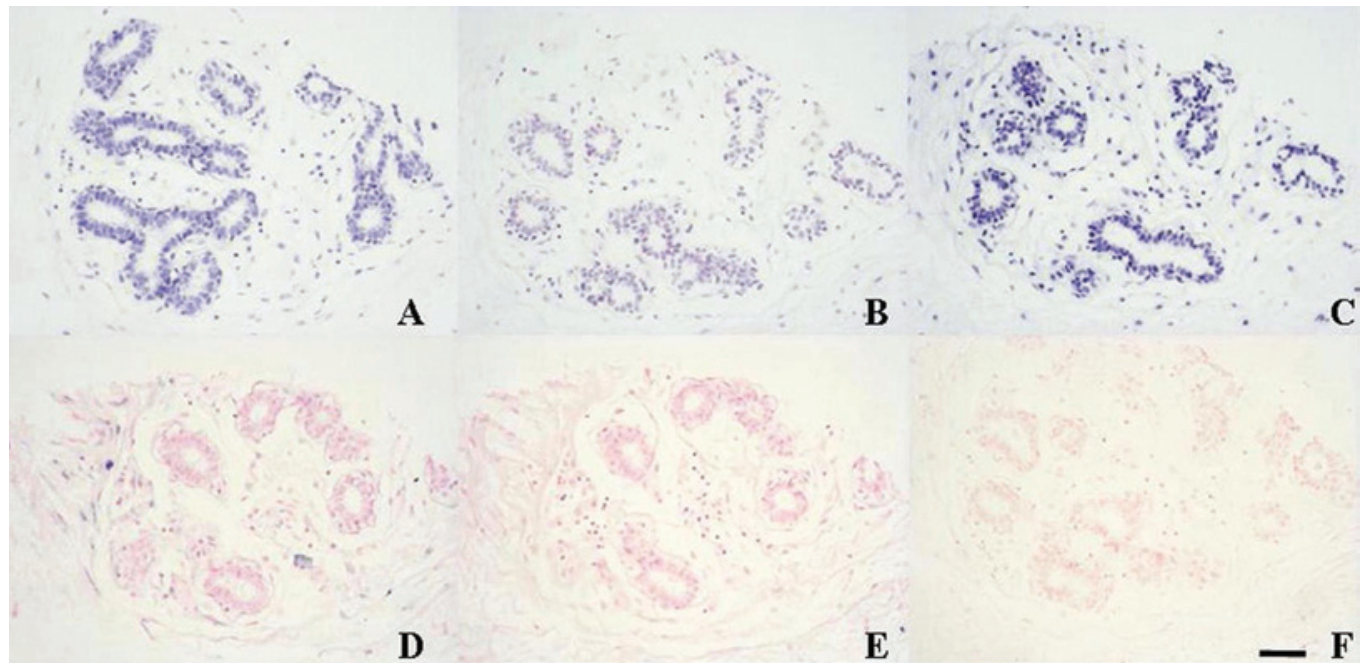

Figure 2. (A-E) RNA in situ hybridization study in normal and negative control. RNA expression of (A) BRCA1, (B) BECN1, (C) CCND1, (D) PTEN and (E) UVRAG. (F) Negative control. Scale bars, $50 \mu \mathrm{m}$.

to the thresholds defined previously between IDC and normal control tissue. The results were assigned intensity and percentage scores based upon the signal intensity of positive staining and the number of cells staining within the sample, respectively (Figs. 1 and 2). Typically, results of the R\&ISH were observed as amethyst positive dots on arrays, located in the cytoplasm or nucleus. Tumor grading was classified according to the World Health Organization System. The presence of occasional tumor cells without detectable overexpression may be attributed to truncated cells that had lost genetic material during sectioning or tissue pre-treatment prior to hybridization.

mRNA expression of genes and its correlation with clinicopathological parameters in IDC. We analyzed significant differences in the in situ hybridization profile of mRNA expression of all genes according to histological grade. For example, positive expression of BRCAl was noted in all 250 cases of IDC and 96 cases of normal breast tissue, $35 / 44$ cases (79.5\%) of early- stage breast carcinoma, $107 / 161$ cases $(66.5 \%)$ with moderate tumor differentiation, $12 / 44$ cases $(26.7 \%)$ with poor tumor differentiation and 84/96 cases $(87.5 \%)$ of normal breast tissue were defined as having positive expression $\left(\chi^{2}=2.083, \mathrm{p}=0.000\right)$. Our study revealed that patients with poor tumor differentiation usually exhibited a lower oncogene expression rate, while patients with well-differentiated tumors always had a higher expression rate. For BECN1, 40/44 (90.9\%) well-differentiated cases showed positive expression, but only $9 / 45$ cases $(20 \%)$ of poorly differentiated carcinoma exhibited BECNI expression. Tumor-suppressor genes, such as BRCAl and BECN1, usually had weaker signals in the carcinomatous tissues (10.2 and 6.6\%) than those in the normal tissues (31 and 32.6\%); stronger positive dots (positive cells $>30 \%$ ) usually existed in normal tissues (Table III). However, the oncogene CCNDI had stronger signals in carcinomatous tissues $(50.4 \%)$ compared to normal tissues (24.2\%) (Fig. 3). Abnormal expression was usually involved in almost all of the tumor cells within the array element. 
Table III. Correlation between mRNA expression of the cancer-related genes and clinicopathological parameters.

\begin{tabular}{|c|c|c|c|c|c|c|c|c|c|c|}
\hline \multirow[b]{2}{*}{ Item } & \multicolumn{2}{|c|}{ BRCAl } & \multicolumn{2}{|c|}{$B E C N 1$} & \multicolumn{2}{|c|}{ CCND1 } & \multicolumn{2}{|c|}{ PTEN } & \multicolumn{2}{|c|}{$U V R A G$} \\
\hline & $\begin{array}{c}\text { Positive } \\
(\%)\end{array}$ & P-value & $\begin{array}{c}\text { Positive } \\
(\%)\end{array}$ & P-value & $\begin{array}{c}\text { Positive } \\
(\%)\end{array}$ & P-value & $\begin{array}{c}\text { Positive } \\
(\%)\end{array}$ & P-value & $\begin{array}{c}\text { Positive } \\
(\%)\end{array}$ & P-value \\
\hline \multicolumn{11}{|c|}{ Histological grading } \\
\hline G1 & $35(79.5)$ & 0.000 & $40(90.9)$ & 0.000 & $43(97.7)$ & 0.000 & $34(77.3)$ & 0.000 & $16(36.4)$ & 0.000 \\
\hline $\mathrm{G} 2$ & $107(66.5)$ & & $72(44.7)$ & & $148(91.9)$ & & $89(55.3)$ & & $13(8.10)$ & \\
\hline G3 & $12(26.7)$ & & $9(20.0)$ & & $17(37.8)$ & & $10(22.2)$ & & $29(64.4)$ & \\
\hline Normal breast & $84(87.5)$ & & $73(76.0)$ & & $75(78.1)$ & & $52(54.2)$ & & $37(38.5)$ & \\
\hline \multicolumn{11}{|l|}{ Age (years) } \\
\hline$<35$ & $17(73.9)$ & 0.158 & $15(65.2)$ & 0.030 & $22(95.7)$ & 0.003 & $12(52.2)$ & 0.900 & $8(34.8)$ & 0.372 \\
\hline $36-60$ & $118(62.4)$ & & $94(49.7)$ & & $161(85.2)$ & & $102(54.0)$ & & $41(21.7)$ & \\
\hline$>60$ & $19(50.0)$ & & $12(31.6)$ & & $25(65.8)$ & & $19(50.0)$ & & $9(23.7)$ & \\
\hline \multicolumn{11}{|l|}{ Tumor extent } \\
\hline pT1 & $14(60.9)$ & 0.028 & $11(47.8)$ & 0.021 & $21(91.3)$ & 0.112 & $14(60.9)$ & 0.630 & $6(26.1)$ & 0.054 \\
\hline pT2 & $94(56.0)$ & & $74(44.0)$ & & $133(79.2)$ & & $85(50.6)$ & & $41(24.4)$ & \\
\hline pT3 & $21(80.8)$ & & $20(76.9)$ & & $24(92.3)$ & & $14(53.8)$ & & $13(50.0)$ & \\
\hline pT4 & $25(75.8)$ & & $16(48.5)$ & & $30(90.9)$ & & $20(60.6)$ & & $8(24.2)$ & \\
\hline \multicolumn{11}{|c|}{ Lymph node status } \\
\hline $\mathrm{pNO}$ & $59(66.3)$ & 0.349 & $45(50.6)$ & 0.619 & $79(88.8)$ & 0.654 & 37 (41.6) & 0.005 & $20(22.5)$ & 0.755 \\
\hline $\mathrm{pN} 1$ & $72(56.7)$ & & $64(50.4)$ & & $111(87.4)$ & & $73(57.5)$ & & $29(22.8)$ & \\
\hline $\mathrm{pN} 2$ & $19(63.3)$ & & $18(60.0)$ & & $28(93.3)$ & & $22(73.3)$ & & $5(16.7)$ & \\
\hline
\end{tabular}

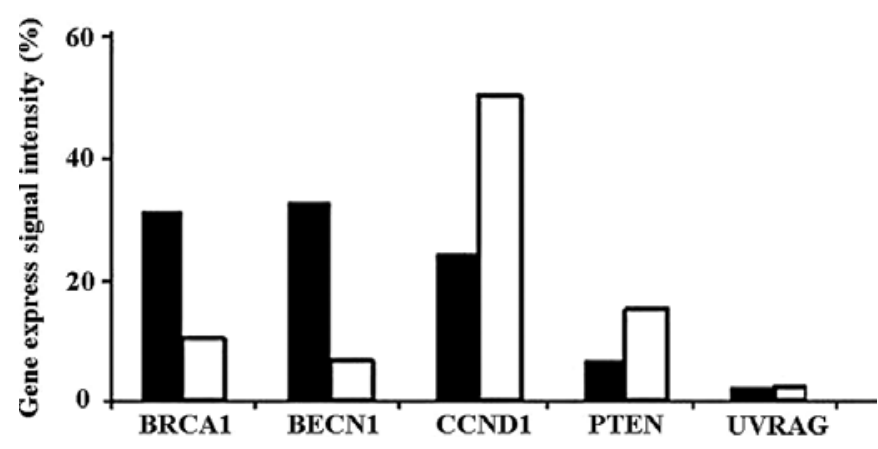

Figure 3. Signal intensity of the gene expression.

Patients were divided into three groups corresponding to age at diagnosis. Each group covered 25-35 years of age. Only BECN1 and CCND1 expression showed a significant association with patient age $(\mathrm{p}=0.030$ and $\mathrm{p}=0.003)$. The patients in the oldest age group had the lowest expression rate.

No significant association was found between CCND1 and $U V R A G$ expression and tumor size and lymph node status. However, a significant association was observed between $B R C A 1$ and BECN1 expression and tumor size ( $\mathrm{p}=0.028$ and $\mathrm{p}=0.021$ ). The cases with a larger tumor size had a higher positive rate of $B R C A 1$ and $B E C N 1$ expression. Tumors $>5.0 \mathrm{~cm}$ showed a positive expression rate of $80.8 \%$ (21/26) for BRCA1, and it was significantly higher compared to the cases with tumors $>2.0 \mathrm{~cm}$, which showed an expression rate of $56 \%$ (94/168). There was a significant association between the PTEN mRNA expression and lymph node metastasis $(\mathrm{p}=0.005)$. A total of 37 out of 89 cases (41.6\%) with no regional lymph node metastasis, $73 / 127$ cases $(57.5 \%)$ with metastasis to movable
Table IV. Expression of BRCA1, BECN1, PTEN and its correlation with $C C N D 1$ expression in IDC.

\begin{tabular}{|c|c|c|c|c|c|c|}
\hline \multirow[t]{2}{*}{ Variables } & \multirow[t]{2}{*}{ No. } & \multicolumn{4}{|c|}{$C C N D 1$} & \multirow[t]{2}{*}{ P-value } \\
\hline & & - & + & ++ & +++ & \\
\hline \multicolumn{7}{|l|}{ BRCAI } \\
\hline- & 96 & 35 & 29 & 12 & 20 & \multirow{4}{*}{0.000} \\
\hline+ & 74 & 3 & 7 & 27 & 37 & \\
\hline++ & 49 & 3 & 5 & 7 & 34 & \\
\hline+++ & 31 & 1 & 6 & 4 & 20 & \\
\hline \multicolumn{7}{|l|}{ BECN1 } \\
\hline- & 129 & 36 & 34 & 27 & 32 & \multirow{4}{*}{0.000} \\
\hline+ & 63 & 5 & 6 & 12 & 40 & \\
\hline++ & 45 & 1 & 4 & 8 & 32 & \\
\hline+++ & 13 & 0 & 3 & 3 & 7 & \\
\hline \multicolumn{7}{|l|}{ PTEN } \\
\hline- & 117 & 33 & 22 & 25 & 37 & \multirow{4}{*}{0.011} \\
\hline+ & 55 & 4 & 6 & 2 & 43 & \\
\hline++ & 40 & 2 & 11 & 12 & 15 & \\
\hline+++ & 38 & 3 & 10 & 9 & 16 & \\
\hline
\end{tabular}

ipsilateral axillary lymph node, whereas $22 / 30$ cases $(73.3 \%)$ with metastasis to ipsilateral axillary lymph node showed expression of PTEN mRNA (Table III).

Expression of BRCA1, BECN1, PTEN and its correlation with $C C N D 1$ expression in IDC. Positive expression of CCND1 was observed in almost all 250 carcinoma cases. A negative 
Table V. Expression of BECNI and its correlation with $U V R A G$ expression in IDC.

\begin{tabular}{llllll}
\hline Variables & No. & \multicolumn{3}{c}{$B E C N 1$} & P-value \\
\cline { 2 - 3 } & & + & ++ & +++ & \\
\hline
\end{tabular}

\begin{tabular}{lrrrrrr}
\hline UVRAG & & & & & & \\
- & 192 & 125 & 33 & 32 & 2 & \\
+ & 43 & 4 & 26 & 11 & 2 & \\
++ & 9 & 0 & 4 & 2 & 3 & 0.006 \\
+++ & 6 & 0 & 0 & 0 & 6 & \\
\hline
\end{tabular}

correlation was observed between $B R C A 1$ and expression of CCNDI ( $\mathrm{p}=0.000)$. For BRCA1, $74(29.6 \%)$ cases showed a weak positively stained cytoplasmic signal and were defined as + and $49(19.6 \%)$ cases and $31(12.4 \%)$ cases were defined as ++ and +++, respectively; however, for CCNDI 47 (18.8\%) cases exhibited a weak positively stained cytoplasmic signal and were defined as + and $50(20.0 \%)$ cases and $111(44.4 \%)$ cases were defined as ++ and +++, respectively. The cases with high $B R C A 1$ tended to have a lower probability of expressing $C C N D 1$. A total of 121 out of 250 cases (48.4\%) demonstrated positive expression of BECN1 and 133/250 cases (53.2\%) demonstrated positive expression of PTEN. BECNI or PTEN showed a significantly negative correlation with $C C N D 1$ expression ( $\mathrm{p}=0.000$ and $\mathrm{p}=0.011)$ in IDC (Table IV).

Expression of BECN1 and its correlation with UVRAG expression in IDC. BECNI binds UVRAG to target the class C Vps complex to coordinate autophagosome maturation and endocytic trafficking. A positive correlation was observed between UVRAG and expression of BECN1 ( $\mathrm{p}=0.006$ ). For BECN1, 63 $(25.2 \%)$ cases showed a weak positively-stained cytoplasmic signal and were defined as + , and $45(18.0 \%)$ cases and $13(5.2 \%)$ cases were defined as ++ and +++ , respectively; in addition, for UVRAG $43(17.2 \%)$ cases were found to have a weak positively stained cytoplasmic signal and were defined as + , while $9(3.6 \%)$ cases and $6(2.4 \%)$ cases were defined as ++ and +++ , respectively. The cases with low UVRAG tended to have a lower probability of expressing $B E C N I$ in IDC (Table V).

Expression of CCND1 and BECN1, and its correlation with PTEN expression in IDC. We observed that the expression of $B E C N 1$ had a positive correlation with the expression of PTEN ( $\mathrm{p}=0.000)$. For BECN1, 63 (25.2\%) cases showed a weak positively stained cytoplasmic signal and were defined as + , while $45(18.0 \%)$ cases and $13(5.2 \%)$ cases were defined as ++ and +++, respectively. In addition, for PTEN 55 (22.0\%) cases exhibited a weak positively stained cytoplasmic signal and were defined as + , while $40(16.0 \%)$ cases and $38(15.2 \%)$ cases were defined as ++ and +++, respectively. The cases with high $B E C N 1$ tended to have a higher probability of expressing $P T E N$ in IDC (Table VI).

\section{Discussion}

TMA technology was used for our study as it allowed the analysis of a large number of samples and markers without
Table VI. Expression of $C C N D 1$ and BECN1 and its correlation with PTEN expression in IDC.

\begin{tabular}{|c|c|c|c|c|c|c|}
\hline \multirow[t]{2}{*}{ Variables } & \multirow[t]{2}{*}{ No. } & \multicolumn{4}{|c|}{ PTEN } & \multirow[t]{2}{*}{ P-value } \\
\hline & & - & + & ++ & +++ & \\
\hline \multicolumn{7}{|l|}{ CCND1 } \\
\hline - & 42 & 33 & 4 & 2 & 3 & \multirow{4}{*}{0.011} \\
\hline+ & 45 & 22 & 6 & 11 & 10 & \\
\hline++ & 48 & 25 & 2 & 12 & 9 & \\
\hline+++ & 115 & 37 & 43 & 15 & 16 & \\
\hline \multicolumn{7}{|l|}{ BECN1 } \\
\hline - & 129 & 81 & 24 & 11 & 13 & \multirow{4}{*}{0.000} \\
\hline+ & 63 & 23 & 22 & 12 & 6 & \\
\hline++ & 45 & 8 & 7 & 15 & 15 & \\
\hline+++ & 13 & 5 & 2 & 2 & 4 & \\
\hline
\end{tabular}

producing methodological variations. Most previous reports on the expression of mRNA have utilized Northern blotting, dot blot or PCR-based approaches, while a few have involved in situ hybridization. Several normal tissues were dominated by adipose cells, differing greatly from tumor tissue in its epithelial cellularity. Normal and tumor tissues may not be rigorously compared by techniques involving RNA extraction from total tissue $(19,20)$. Therefore, conclusions such as 'increased expression' may be more difficult to make from studies with Northern blotting, dot blot and PCR-based techniques that require RNA extraction from tissues that have not been fastidiously micro-dissected for the selection of tumor cells. All probes theoretically detect mRNA expression of wild-type and a great majority of mutant type genes, if transcriptionally active, since the oligonucleotide recognizes the DNA sequence near the $5^{\prime}$ end in which mRNA transcription is considered to start. The data on BRCA1, BECN1, CCND1, PTEN and UVRAG RNA in situ hybridization most commonly studied in associated tumors were similar to those reported previously (21-25). In addition, certain tissue positive rates were higher than previous reports, confirming the usefulness of the TMA approach.

In this study, all cases showed significant differences between gene expression and histological grade $(\mathrm{p}=0.000)$. The well-differentiated and normal breast tissue usually had a higher positive rate, while the poorly differentiated tissue always had a lower positive rate. For the expression of PTEN mRNA, 34/44 (77.3\%) cases with well-differentiated tumors, and 52/96 (54.2\%) normal controls showed positive signals, while the moderately and poorly differentiated breast carcinoma cases had a rate of PTEN expression of 55.3 and 22.2\%, respectively. Tumor-suppressor genes, such as $B R C A l$ and $B E C N 1$, usually had weaker signals (positive cells $<30 \%$ ) in carcinomatous tissues (10.2 and 6.6\%) than those in the normal tissue (31 and 32.6\%), while stronger positive dots (positive cells $>30 \%$ ) usually existed in normal tissue. By contrast, the oncogene $C C N D 1$ had stronger signals in carcinomatous tissues (50.4\%) compared to those in normal tissues (24.2\%). We hypothesized that the abnormal expression of BRCAl, $B E C N 1, C C N D 1, P T E N$ and $U V R A G$ may play a key role in 
human breast carcinogenesis through regulating expression of its mRNA; overexpression of CCNDI may contribute to the formation of IDC, however, normally expressed $B R C A 1$, $B E C N 1$ and PTEN in breast cancer may block the formation of IDC. The results of Steeg and Zhou (7) showed that CCNDI has been found to be overexpressed in $40-50 \%$ of invasive breast cancers and amplified in 10-20\% of cases. Expression of CCND1 was found to play a significant role in the early staging of carcinogenesis in Caucasian females with breast carcinoma. We believe that the expression of $C C N D 1$ plays the same role in Chinese patients with breast carcinoma.

Only BECN1 and CCND1 expression showed a significant association with patient age $(\mathrm{p}=0.030$ and $\mathrm{p}=0.003)$. The patients in the oldest age group had the lowest expression rate. In addition, a significant association was observed between $B R C A 1$ and BECNI expression and tumor size ( $\mathrm{p}=0.028$ and $\mathrm{p}=0.021)$. The PTEN mRNA expression had a significant association with lymph node metastasis $(\mathrm{p}=0.005)$.

The cell cycle is crucial for the control of growth in cells and that is just what cancer is, a loss in the control of cell growth. The genes BRCA1, BECN1, CCND1 and PTEN are involved in cell cycle regulation. The $C C N D 1$ gene codes for a cell cycle protein which specifically acts during the G1 phase; upon interaction with cyclin-dependent kinases (CDK4 or CDK6) CCND1 phosphorylates the p105-RB protein and thereby promotes progression in late G1, thus favoring entry into the $\mathrm{S}$ phase. Ectopic overexpression of $C C N D 1$ has been shown to result in a shortened G1 phase and increased genetic instability, possibly due to a bypass of cell cycle checkpoints (26). BRCAl is involved in all phases of the cell cycle and regulates orderly events during cell cycle progression. BRCA1 deficiency consequently causes abnormalities in the S-phase checkpoint, the $\mathrm{G}_{2} / \mathrm{M}$ checkpoint, and the spindle checkpoint and centrosome duplication (27). PTEN may induce a specific reduction in cyclin D3 levels and an associated increase in the amount of the inhibitor $\mathrm{p} 27^{\mathrm{KIP} 1}$ complexed with CDK2. Enforced expression of cyclin D3 was found to abrogate the PTEN-induced cell cycle arrest (28). BECN1 inhibits the growth of cancer cells and decreases the expression levels of cyclin $\mathrm{E}$ and phosphorylated $\mathrm{Rb}$. The present results showed that BRCA1, PTEN and BECN1 had a significantly negative correlation with positive expression of CCND1. These cases had a higher CCND1 mRNA expression and a lower suppressor gene expression was observed, which is thought to be an imbalance in the CCND1/CDK complex or to decrease the nuclear availability of $C C N D 1$ through the Akt/PKB pathway.

Autophagy is characterized by sequestration of bulk cytoplasm and organelles in double or multimembrane autophagic vesicles, and their delivery to and subsequent degradation by the cell's own lysosomal system. A number of studies have raised the possibility that the breakdown of the autophagic process may contribute to the development of cancer. UVRAG is a BECN1-interacting protein. UVRAG association with $B E C N 1$ enhances phosphatidylinositol-3-OH kinase class III [PI(3)KC3] activity and induces autophagosome formation. Our results showed that $B E C N 1$ was markedly associated with positive expression of $U V R A G(\mathrm{p}=0.006)$. These results agree with the conclusion of other investigators. The results of Liang et al (17) showed that the UV irradiation resistance-associated gene is a positive regulator of the BECN1-PI(3)KC3 complex and may monoallelically mutate at a high frequency in human colon cancers, and associate with the BECN1-Bcl-2-PI(3) KC3 multiprotein complex, where $U V R A G$ and BECN1 interdependently induce autophagy $(29,30)$. We hypothesized that the loss-balance expression of $U V R A G$ and BECN1 may affect normal cells in the process of autophagy which has an accelerating role in the breast carcinogenesis of Chinese women.

Apoptosis is the process of programmed cell death (PCD) and a frequent phenomenon in breast cancer. The apoptotic process is controlled by inducers and repressors, and the balance between these stimuli determines whether the cell cycle enters mitosis or apoptosis. PTEN and BECN1 induce cell apoptosis, but CCND1 shortens the G1 phase, increases genetic instability and bypasses cell cycle checkpoints. Our study revealed that the expression of PTEN was positively correlated to the expression of BECN1 $(p=0.000)$, and had a negative correlation with the expression of CCND1 $(\mathrm{p}=0.011)$. PTEN-induced apoptosis is achieved mainly through its lipid phosphatase activity. PTEN through the PI3K/AKT signal transduction pathway from phosphoric acid reduces the level of AKT. AKT reduces the apoptosis factor and enhances the activity of anti-apoptotic protein. Excessive activation of AKT induces cells to lose their ability of apoptosis. By contrast, a PTEN-deficiency is likely to boost the Akt pathway, while the deficient cells show a significantly reduced sensitivity to agonist-induced apoptosis (31). We believe that the abnormal expression of the tumor-suppressor genes (BECN1 and PTEN) and up-regulated oncogenes (CCNDI) may disrupt apoptosis, leading to tumor initiation, progression or change in the promotion of apoptosis, thereby producing selective pressure to override apoptosis during multi-stage carcinogenesis. Finally, as a factor closely related to cancer, CCND1 should open up new avenues for the study of the multi-step process of human breast carcinogenesis, since $C C N D 1$, known as an oncogene involved in the cell cycle, apoptosis and a number of other biological functions, is frequently up-regulated in numerous tumor types (32). It would be of utmost interest to determine whether CCNDI is overexpressed in IDC and, if so, the overexpression of this oncogene may be considered as one of the most crucial early events in altered tumor tissues.

Cell cycle regulation, autophagy and apoptosis are closely linked to cancer. If genes that control cell cycle regulation, autophagy and apoptosis are overexpressed or expression is absent, normal breast cells may be altered into cancer cells. It would be meaningful to analyze lower grade tumors and premalignant lesions using the same measurement tools, to determine whether the oncogene and suppressor gene expression is different, comparing various steps in the onset and progression of the disease. Follow-up is currently being carried out to obtain information on 5-year survival rates of the patients and the protein level of those genes by immunohistochemical staining. Data will be provided in our subsequent study.

In conclusion, abnormal expression of BRCA1, BECN1, $C C N D 1, P T E N$ and $U V R A G$ may play a role in human breast carcinogenesis through dysregulated mRNA expression. Overexpressed CCND1 may shorten the G1 phase, suppress cell apoptosis and contribute to the formation of IDC. 


\section{Acknowledgements}

This study was supported by the National Natural Science Foundation of China (no. 30972930, 81100440).

\section{References}

1. World Health Organization International Agency for Research on Cancer (June 2003): 'World Cancer Report'. http://www. iarc.fr/en/Publications/PDFs-online/World-Cancer-Report/ World-Cancer-Report. Retrieved on March 26, 2009.

2. World Health Organization (February 2006): 'Fact sheet No. 297: Cancer'. http://www.who.int/mediacentre/factsheets/fs297/ en/index.html. Retrieved on March 26, 2009.

3. Lam WW, Fielding R and Ho EY: Predicting psychological morbidity in Chinese women following surgery for breast cancer. Cancer 103: 637-646, 2005.

4. Cavalieri E, Chakravarti D, Guttenplan J, et al: Catechol estrogen quinones as initiators of breast and other human cancers: implications for biomarkers of susceptibility and cancer prevention. Biochim Biophys Acta 1766: 63-78, 2006.

5. Farlex (2005): 'Immunological surveillance, The Free Dictionary: Immunological Surveilliance'. http://medical-dictionary.thefreedictionary.com/immunological+surveillance immunological surveillance. Retrieved on February 10, 2008.

6. Braddock, Suzanne W, Kercher J and Clark M: Straight Talk About Breast Cancer From Diagnosis to Recovery: A Guide for the Whole Family. Addicus Books, Omaha, 1994.

7. Steeg P and Zhou Q: Cyclins and breast cancer. Breast Cancer Res Treat 52: 17-28, 1998.

8. Loden M, Stighall M, Nielsen NH, et al: The cyclin D1 high and cyclin $\mathrm{E}$ high subgroups of breast cancer: separate pathways in tumorigenesis based on pattern of genetic aberrations and inactivation of the pRb node. Oncogene 21: 4680-4690, 2002.

9. Miki Y, Swensen J, Shattuck-Eidens D, et al: A strong candidate for the breast and ovarian cancer susceptibility gene BRCA1. Science 266: 66-71, 1994.

10. Bienstock RJ, Darden T, Wiseman R, et al: Molecular modeling of the amino-terminal zinc ring domain of BRCA1. Cancer Res 56: 2539-2545, 1996.

11. Scully R, Chen J, Ochs RL, et al: Dynamic changes of BRCA1 subnuclear location and phosphorylation state are initiated by DNA damage. Cell 90: 425-435, 1997.

12. Simpson L and Parsons R: PTEN: life as a tumor suppressor. Exp Cell Res 264: 29-41, 2001.

13. Mills GB, Lu Y, Fang X, et al: The role of genetic abnormalities of PTEN and the phosphatidylinositol 3-kinase pathway in breast and ovarian tumorigenesis, prognosis and therapy. Semin Oncol 28: 125-141, 2001.

14. Nelen MR, Staveren WC, Peeters EA, et al: Germline mutations in the PTEN/MMAC1 gene in patients with Cowden disease. Hum Mol Genet 6: 1383-1387, 1997.

15. Aita VM, Liang XH, Murty VV, et al: Cloning and genomic organization of Beclin 1, a candidate tumor suppressor gene on chromosome 17q21. Genomics 59: 59-65, 1999.
16. Duan ZL, Peng ZL and Wang ZH: [Expression and involved signal transduction pathway of autophagy gene Beclin-1 in epithelial ovarian cancer]. Sichuan Da Xue Xue Bao Yi Xue Ban 38: 239-242, 2007 (In Chinese).

17. Liang C, Feng P, Ku B, et al: Autophagic and tumour suppressor activity of a novel Beclin1-binding protein UVRAG. Nat Cell Biol 8: 688-699, 2006.

18. Francesco C and Beth L: The role of autophagy in mammalian development cell makeover rather than cell death. Dev Cell 15: 344-357, 2008.

19. Kononen J, Bubendorf L, Kallioniemi A, et al: Tissue microarrays for high-throughput molecular profiling of tumor specimens. Nat Med 4: 844-847, 1998.

20. Battifora $\mathrm{H}$ : The multitumor (sausage) tissue block: novel method for immunohistochemical antibody testing. Lab Invest 55: 244-248, 1986

21. Walsh T, Casadei S, Coats KH, et al: Spectrum of mutations in BRCA1, BRCA2, CHEK2, and TP53 in families at high risk of breast cancer. JAMA 295: 1379-1388, 2006.

22. Lee JW, Jeong EG, Lee SH, Yoo NJ, Lee SH: Somatic mutations of BECN1, an autophagy-related gene, in human cancer. JAMA 115: 750-756, 2007.

23. Liu GY, Luo Q, Xiong B, et al: Tissue array for Tp53, C-myc, CCND1 gene over-expression in different tumors. World J Gastro 47: 7199-7207, 2008.

24. Di Vizio D, Cito L, Boccia A, et al: Loss of the tumor suppressor gene PTEN marks the transition from intratubular germ cell neoplasias (ITGCN) to invasive germ cell tumors. Oncogene 24: 1882-1894, 2005

25. Knaevelsrud H, Ahlquist T, Merok MA, et al: UVRAG mutations associated with microsatellite unstable colon cancer do not affect autophagy. Autophagy 7:863-870, 2010.

26. Bautista S and Theillet C: CCND1 and FGFR1 coamplification results in the colocalization of $11 \mathrm{q} 13$ and $8 \mathrm{p} 12$ sequences in breast tumor nuclei. Genes Chromosomes Cancer 22: 268-277, 1998.

27. Deng CX: BRCA1: cell cycle checkpoint, genetic instability, DNA damage response and cancer evolution. Nucleic Acids Res 34: 1416-1426, 2006.

28. Zhu XY, Kwon CH, Peter W, et al: PTEN induces G1 cell cycle arrest and decreases cyclin D3 levels in endometrial carcinoma cells. Cancer Res 61: 4569-4575, 2001.

29. Itakura E, Kishi C, Inoue $\mathrm{K}$ and Mizushima N: Beclin 1 forms two distinct phosphatidylinositol 3-kinase complexes with mammalian Atg14 and UVRAG. Mol Biol Cell 19: 5360-5372, 2008.

30. Cheng L and Lee JS: Beclin1-binding UVRAG targets the class C Vps complex to coordinate autophagosome maturation and endocytic trafficking. Nat Cell Biol 10: 776-787, 2008.

31. Vivanco I and Sawyers CL: The phosphatidylinositol 3-kinase AKT pathway in human cancer. Nat Rev Cancer 2: 489-501, 2002.

32. Burnworth B, Popp S, Stark H-J, et al: Gain of 11ql[sol]lcyclin D1 overexpression is an essential early step in skin cancer development and causes abnormal tissue organization and differentiation. Oncogene 25: 4399-4412, 2006. 